\title{
ON THE RELATIVE ROLE OF THE SCUTELLUM AND ALEURONE IN THE PRODUCTION OF HYDROLASES DURING GERMINATION OF BARLEY
}

\author{
by \\ GREGORY C. GIBBONS \\ Carlsberg Research Laboratory, Department of Biotechnology, \\ Gamle Carlsberg Vej 10, DK-2500 Copenhagen Valby
}

Keywords: Gibberellic acid, abscisic acid, abrasion, $\alpha$-amylase, $\beta$-glucan, cell wall

The relative roles of the scutellum and the aleurone layer in the production and mediation of both germination-specific $\alpha$-amylase and cell wall breakdown hydrolases has been examined in vivo following treatment of barley seeds with the plant hormones gibberellic acid and abscisic acid. To facilitate entry of these exogenous hormones, a technique is presented where multiple incisions (mnicks ) are made in the outer layers of the seed prior to germination. Treatment of seeds with gibberellic acid and abscisic acid effected major changes on the pattern of hydrolase transport. The nature of the changes were such that it is concluded that the scutellum alone is capable of producing and mediating up to $50 \%$ of germination specific hydrolases in a commercial European malting barley, germinating at the conventional European malting temperature of $15{ }^{\circ} \mathrm{C}$.

\section{INTRODUCTION}

It is well established that in barley caryopsis both the scutellum and the aleurone layer are involved in the production and mediation of hydrolytic enzymes during germination $(4,5,9$, $10,16,20,25)$.

The relative role of these two tissues in the synthesis and dissemination of hydrolytic enzymes has been a subject of much discussion for a period of almost one hundred years $(3,9,11$, $16,20,25)$. A variety of experimental techniques have been utilised in attempts to elucidate the relative contributions of both tissues: dissection followed by incubation in the presence of either plant hormones $(7,18,19)$ or an sendospermlike « substrate (10); inflicting lesions to the one tissue and thereafter measuring the contribution of the other (2); simple histochemical observation of thin sections $(5,16,20,25)$.

None of these techniques have conclusively answered the question, and depending on the system employed, some authors have claimed 
that the scutellum is the major contributor of hydrolases during germination, while others have concluded that the aleurone is solely responsible.

The development of reproducible whole-seed sectioning techniques and immunohistochemical or fluorescence-histochemical methods $(11,12)$ have permitted observations to be made of the entire process of hydrolase production and subsequent dissemination in an easily interpretable way. In the present paper these techniques have been used in an attempt to clarify the relative role of the scutellum and of the aleurone in germinating barley seeds.

\section{MATERIALS AND METHODS}

\subsection{Chemicals}

Calcofluor white M2R new (di-sodium 4,4'bis (4-anilinobis - 2 - hydroxy - ethyl amino - S - triazin - 2 ylamino) - 2,2' - stilbenedisulphonate) was obtained from Cyanamid, U.S.A. via Struers, Denmark. Fast Green F. C. F. (Fast Green 3; C. 1. 42053; lot 17761) was obtained from Hopkin and Williams, Chadwell Heath, Essex, England. 96\% ethanol was obtained from De Danske Spritfabrikker, Denmark, and fluorescence-free glycerol was from Merck, West Germany.

Gibberellic acid (grade III, minimum content Gibberellin A3, 90\%, lot No. 98c-0008) and \pm cis-trans abscisic acid (grade IV, approx. 95\%, lot No. 86c-3778) were obtained from Sigma Chemical Company, St. Louis, Mo., U.S.A.

All other reagents were of analytical grade.

\subsection{Plant material}

Seeds of hordeum vulgare L. (cv. Nordal) were obtained from the 1980 harvest at the Carlsberg Plant Breeding research station, Allindemaglegård. Seeds were fractionated on a MiniPetkus laboratory sorting machine (Schule, Hamburg, West Germany) and the fraction retained between $2.85 \mathrm{~mm}$ and $3.00 \mathrm{~mm}$ was stored at room temperature and used for all experiments. Seeds were pushed into sterile sand $(100 \mathrm{~g})$ in a sterile petri dish. $21 \mathrm{ml}$ of the appropriate hormone solution or distilled water were added and the seeds germinated in a darkened room for the required time at $15^{\circ} \mathrm{C}$ ( $98 \%$ relative humidity).

\subsection{Tissue preparation}

For histochemical work, seeds were removed from the germinating dishes and fixed in 10\% paraformaldehyde-lysine-periodate fixative as described previously (11). In the experiment where multiple incisions (nicks) were applied to the seeds prior to germination, no further incisions were made prior to fixation. Following washing and freezing at $-20^{\circ} \mathrm{C}, 15 \mu$ sections were made on a Reichert-Jung Frigocut 2700 Cryotome (Jung, Heidelberg, West Germany) and transferred to gelatine-coated sides. The sections were dried in vacuo $\left(10^{-2}\right.$ torr) prior to staining.

For image analysis seeds were removed from the germinating dishes and stored at $-20^{\circ} \mathrm{C}$. Seeds were halved longitudinally, and stained in calcofluor/fast green as described previously (13).

\subsection{Image analysis}

Image analysis was performed as described by Aastrup and Erdal ( 1 ) on Reichert Polyvar microscope (Reichert, Austria) coupled to a Quantimet 720 image analyser (Cambridge Instruments, Melbourne, England) and a Hewlett Packard 9835 computer (Hewlett Packard, U.S.A.).

\subsection{Immunohistochemical methods}

Immunohistochemical localisation of the de novo sythesised $\alpha$-II- $\alpha$-amylase was performed as described by GibBons (11).

\subsection{Cell wall breakdown measurement}

The action of cell wall hydrolases was followed using the calcofluor/fast green method described by GibBons $(12,13)$.

\subsection{Fluorescence microscopy}

Fluorescence microscopy was performed using an American Optical Stereostar zoom microscope (American Optical, Southbridge, 
Mass., U.S.A.) equipped with a Carlsberg Macrofluorescence Microscope Unit (Carlsberg, Copenhagen, Denmark). For immunohistochemistry, excitation was effected with a BP 450$490 \mathrm{~nm}$ filter and the emitted light observed with an LWP $515 \mathrm{~nm}$ filter. For cell wall measurements an SWP 400nm exciter filter, and a Schott (West Germany) KV418 emission filter. Interference filters (both SWP, BP, and LWP) were obtained from Optisk Laboratiorium (Lundtofte, Denmark).

Photomicrographs were obtained with an Expostar photography accessory from American Optical (U.S.A.). Ektachrome 400 EL (Kodak, Rochester, N.Y., U.S.A.) was used for all exposures.

\section{RESULTS AND DISCUSSION}

\subsection{Distal decapitation experiment}

Previously it has been demonstrated that distal decapitation of barley seeds followed by germination in the presence of gibberellic acid, results in activation of the distal aleurone cells. After a lag period, these cells produce and disseminate both $\alpha$-II- $\alpha$-amylase and cell wall hydrolases (12). In contrast, production and dissemination of hydrolases from the scutellum appeared to be largely unaffected by the addition of exogenous gibberellic acid. The results indicated that the scutellar hydrolase system was under a different set of control mechanisms than that of the aleurone layer. To further investigate this apparent differential effect of gibberellic acid, an experiment was carried out in which the plant hormone abscisic acid, a well documented inhibitor of the gibberellic acid-induced formation of hydrolases in barley aleurone tissue $(2,6$, $17,26)$, was added to distally decapitated seeds germinating in the presence of gibberellic acid. Both distally decapitated and whole seeds were germinated for up to 7 days in either water, $10 \mu \mathrm{M}$ gibberellic acid or a mixture of $10 \mu \mathrm{M}$ gibberellic acid and $50 \mu \mathrm{M} \pm$ cis-trans abscisic acid. The chosen ratio between the two hormones had been determined on the basis of previously published reports where abscisic acid had been used to inhibit gibberellic acidstimulated hydrolase production $(6,26)$.

The results of this experiment (presented as selected individual sections in Figure 1 and quantified in Table I) demonstrate conclusively the ability to abscisic acid to negate the stimulatory effect of gibberellic acid on the distal aleurone layer. In the control seeds (Row A) cell wall breakdown was seen to proceed in the manner previously described (12). An initial spreading of cell wall hydrolytic activity in a broad band from the face of the scutellum was seen up to day 4 . From day 5 a marked increase in aleurone-mediated cell wall hydrolytic activity was observed, as evidenced by large amounts of cell wall breakdown under this tissue in the distal end of the seed. By the 7th day all endosperm cell walls containing calcofluor stainable material ( $\beta$-glucan) had been digested.

When whole seeds were treated with gibberellic acid (Row B) the effect of the hormone was clearly seen by the 6th day where accelerated aleurone activity, stimulated by the hormone, resulted in total hydrolysis of the endosperm cell walls approximately one day earlier than in the control seeds. The combination of gibberellic acid and abscisic acid (Row C) resulted in a marked inhibition of aleurone activity in the distal aleurone cells. It was clear, however, that some aleurone activity occurred. The probable explanation for this lesser aleurone activity is that abscisic acid was metabolised to a glucosidic form which lacked anti-gibberellic acid activity $(14,26)$. Such metabolism of abscisic acid by barley aleurone layers has been reported by W ALTON's group (8).

Distal decapitation of the seed followed by germination in the absence of inhibitors (Row D) did not affect the process of cell wall breakdown markedly. Treatment of distally decapitated seeds with gibberellic acid (Row E) resulted in an activation of the distal aleurone cells, evident on the third day of germination. The hormone rapidly entered through the cut distal end of the seed and, after stimulating the aleurone layer to produce hydrolases, effected a massive breakdown of the central endosperm. Abscisic acid (Row F) inhibited the gibberellic acid response in the distal end of the seed. Cell wall breakdown was observed under the median aleurone layer from the fourth day, indicating that either the transport of abscisic acid to this area was in some way inhibited, or as mentioned previously, the distal aleurone cells had metabolised the hormone to a non-active form. 
DAY 2
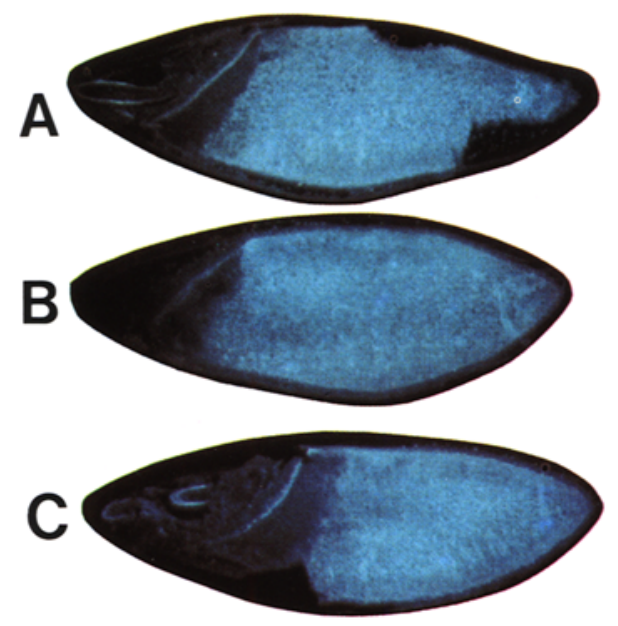

D
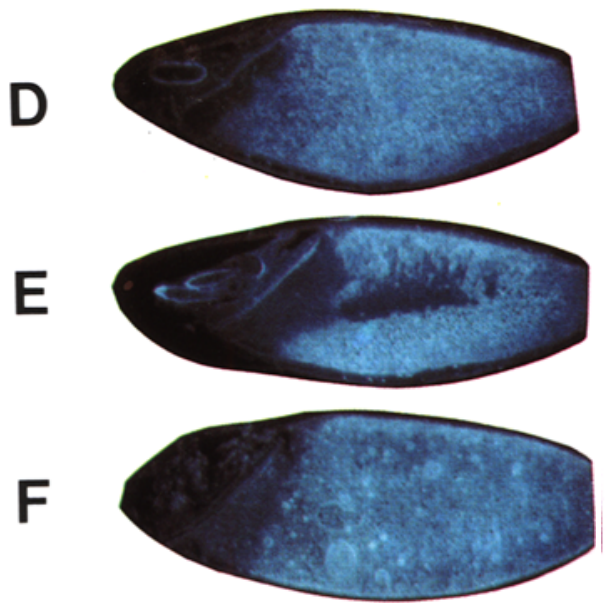

DAY 3
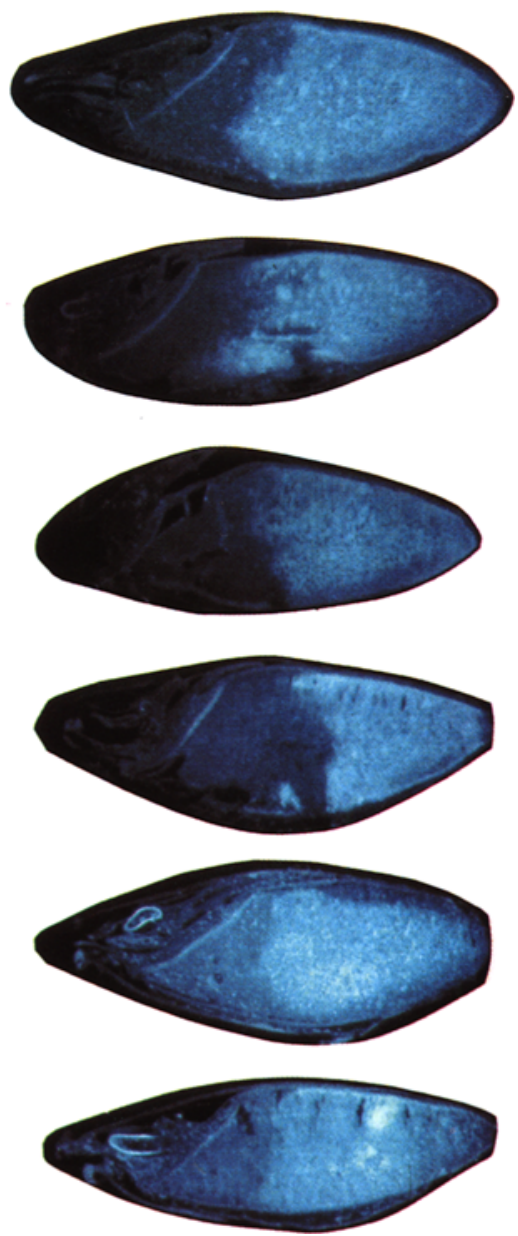

DAY 4
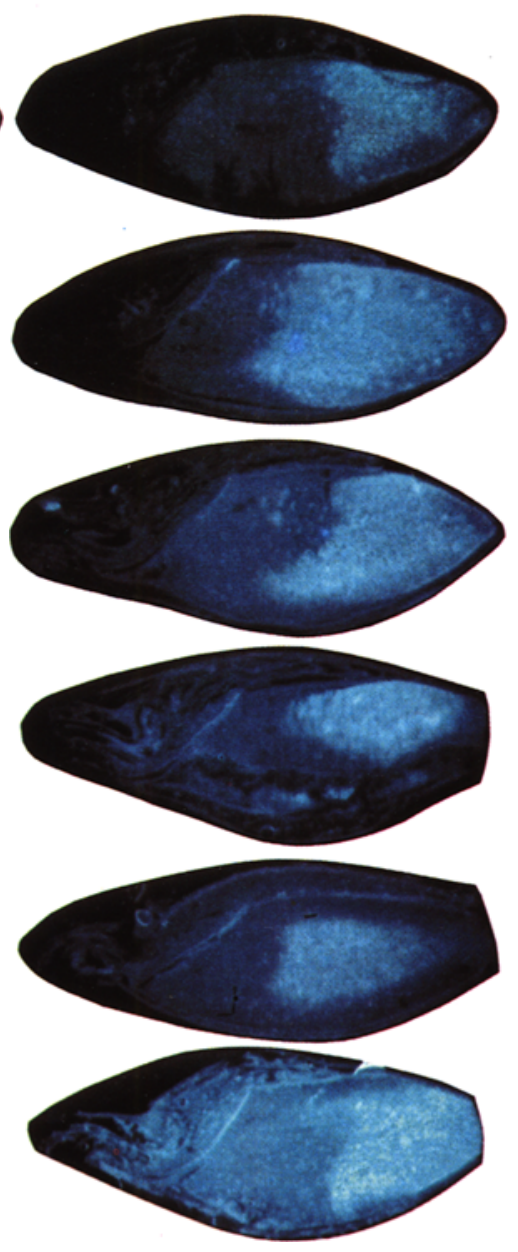

Figure 1. The effect of plant hormones on seed germination.

Whole barley seeds or seeds in which the distal tip had been removed (decapitation) were germinated at $15^{\circ} \mathrm{C}$ on moist sand in the presence or absence of plant hormones. Following thin sectioning cell wall breakdown was visualised with calcofluor as described in section 2.6. Legend $\mathrm{A}=$ whole seeds, distilled water; $\mathrm{B}=$ whole seeds, $10 \mu \mathrm{M}$-gibberellic acid; $\mathrm{C}=$ whole seeds, $10 \mu \mathrm{M}$-gibberellic acid and $50 \mu \mathrm{M}$-abscisic acid; $\mathrm{D}=$ distally decapitated seeds, distilled water; $E=$ distally decapitated seeds, $10 \mu \mathrm{M}$-gibberellic acid; $\mathrm{F}=$ distally deçapitated seeds, $10 \mu \mathrm{M}-$ gibberellic acid and $50 \mu \mathrm{M}$-abscisic acid. 
DAY 5
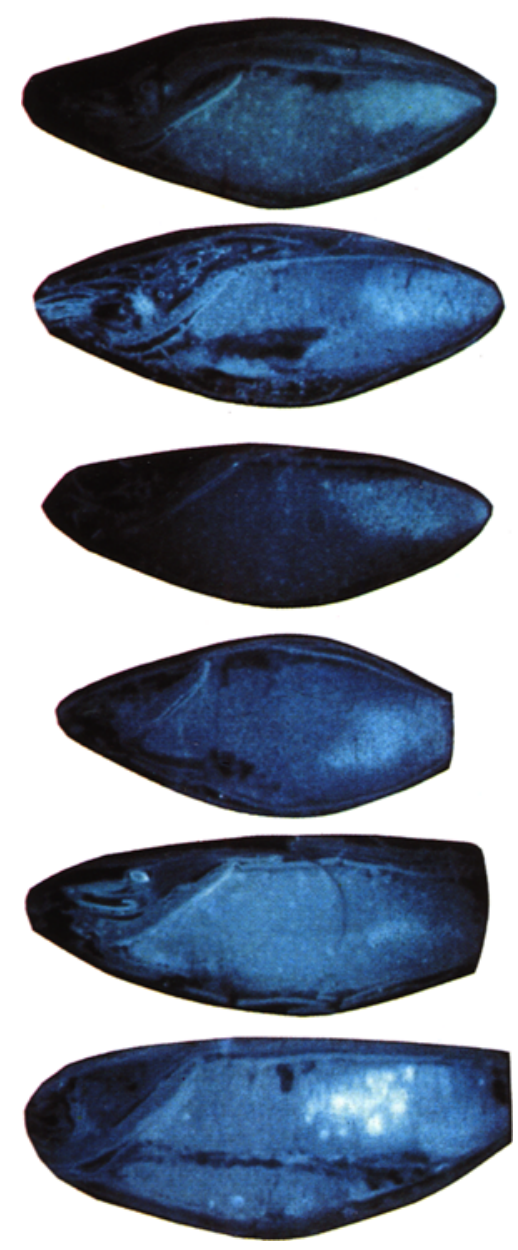

DAY 6
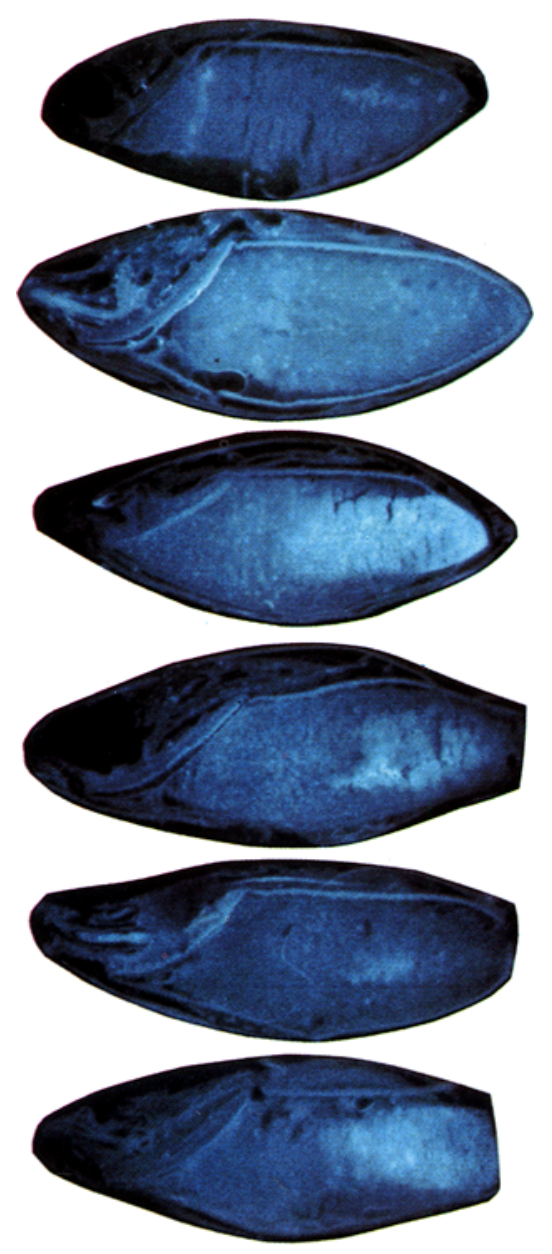

DAY 7
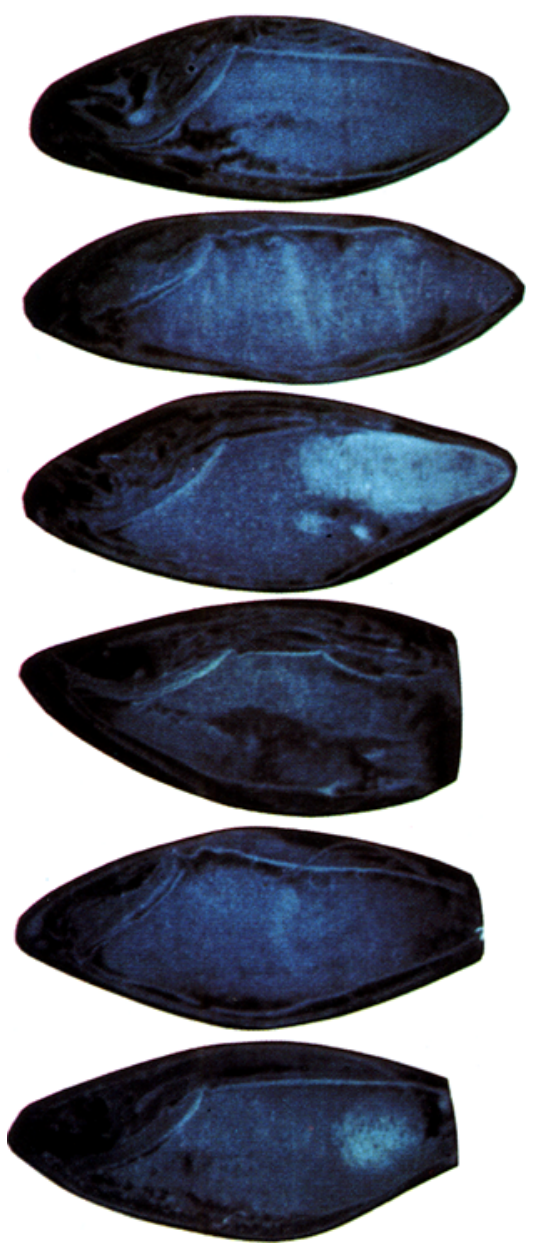

For the purpose of comparison with Table I the actual cell wall breakdown percentages of the sections presented in this figure as follows:

Day 2 from A to F: 11, 10, 19, 11, 16, 16;

Day $3 \quad$ : $25,26,33,44,39,27$;

Day $4 \quad " \quad: 54,33,46,47,69,50$

Day $5 \quad " \quad: 78,78,76,80,96,65$;

Day $6 \quad ": 96,100,62,84,95,62$;

Day $7 \quad$ : $100,100,68,100,100,77$. 
Table I

Image analysis of cell wall breakdown.

\begin{tabular}{|c|c|c|c|c|c|c|c|}
\hline Treatment & $\mathrm{CON}$ & $\mathrm{GA}_{3}$ & $\begin{array}{c}\mathrm{GA}_{3} \\
+\mathrm{ABA}\end{array}$ & $\mathrm{DD}$ & $\mathrm{DD}+\mathrm{GA}_{3}$ & $\begin{array}{c}\mathrm{F} \\
\mathrm{DD}+\mathrm{GA}_{3} \\
+\mathrm{ABA}\end{array}$ & $\begin{array}{c}\text { Standard } \\
\text { error } \\
\text { for all } \\
\text { treatments }\end{array}$ \\
\hline DAY 2 & $9 \cdot 7$ & 8.9 & $7 \cdot 7$ & 6.6 & $7 \cdot 1$ & 6.9 & $\leq 5 \cdot 3$ \\
\hline DAY 3 & $17 \cdot 8$ & $24 \cdot 4$ & $17 \cdot 4$ & $21 \cdot 5$ & $23 \cdot 5$ & 17.6 & $\leq 13 \cdot 4$ \\
\hline DAY 4 & $51 \cdot 6$ & $47 \cdot 1$ & 36.9 & 45.0 & $75 \cdot 3$ & $40 \cdot 2$ & $\leq 11 \cdot 9$ \\
\hline DAY 5 & $64 \cdot 3$ & $70 \cdot 0$ & $59 \cdot 5$ & 62.7 & $82 \cdot 2$ & $56 \cdot 3$ & $\leq 11 \cdot 2$ \\
\hline DAY 6 & $80 \cdot 5$ & $89 \cdot 1$ & $72 \cdot 5$ & $78 \cdot 5$ & $92 \cdot 1$ & $74 \cdot 4$ & $\leq 13.0$ \\
\hline DAY 7 & 94.7 & 96.4 & $88 \cdot 9$ & $89 \cdot 8$ & $95 \cdot 7$ & 81.8 & $\leq 14.4$ \\
\hline
\end{tabular}

Image analysis of seeds of Nordal barley germinating in the presence of inhibitors both with and without distal decapitation. $\mathrm{CON}=$ control, whole seeds germinated in distilled water; $\mathrm{GA}_{3}=$ whole seeds germinated in $10 \mu \mathrm{M}$ gibberellic acid $\mathrm{GA}_{3} ; \mathrm{GA}_{3}+\mathrm{ABA}=$ whole seeds germinated in $10 \mu \mathrm{M}-\mathrm{GA}_{3}$ and $50 \mu \mathrm{M}$ abscisic acid; $\mathrm{DD}=$ distal decapitation, distilled water; $D D+G_{3}=$ distal decapitation, $10 \mu \mathrm{M}-\mathrm{GA}_{3} ; \mathrm{DD}+\mathrm{GA}_{3}+\mathrm{ABA}=$ distal decapitation, $10 \mu \mathrm{M}-\mathrm{GA}_{3}$ plus $50 \mu \mathrm{M}$ abscisic acid.

All values are expressed as the means of 30 separate seeds for each day/treatment. The standard error is expressed as the highest value for any treatment on the day in question.

The results presented in Figure 1 have been chosen to give a representative picture of the sections obtained from the fixed seeds. On account of the unavoidable biological variation, it was however necessary to obtain some measure of the degree of variation within treatments. In order to obtain quantitative data about this biological variation, image analysis was performed on 30 seeds from each treatment/day.

Image analysis (Table I) confirmed the results seen in Figure 1. There was no significant difference between treatments until the fourth day where the distally decapitated seeds treated with gibberellic acid exhibited evidence of rapid cell wall breakdown. The inhibitory effect of abscisic acid on this gibberellic acid-stimulated cell wall hydrolase synthesis was most apparent on the fourth, fifth and sixth days.

$\alpha$-II- $\alpha$-amylase transport patterns were similar to the observed cell wall breakdown. The immunohistochemical results for 4 days and 6 days germination (Figure 2) illustrate the ability of abscisic acid to negate the stimulatory effect of gibberellic acid on distal aleurone $\alpha$-II- $\alpha$-amylase production and transport.

It is of interest to note that in all seeds sectioned, the dorsal endosperm remained attached to the scutellum. There was no evidence of increased dorsal aleurone activity in the me- diation of either cell wall breakdown or $\alpha$-II- $\alpha$ amylase synthesis. PaLmer (22) has postulated exclusively dorsal breakdown on the basis of warm water washing of dried barley malt grains. During the washing procedure starch and protein are selectively removed from the dorsal area of the endosperm thereby producing a dorsal »hole« $(13,22)$. More recently the same author has presented micrographs showing an apparent increasing degree of weakness in the cell walls of the dorsal region of the endosperm in fixed sections of barley during the early stages of germination (23). Our examination of more than 26,000 half seed sections using the calcofluor technique, indicates that the appearance of a dorsal »hole « or selective separation of the dorsal endosperm from the aleurone layer and scutellum appears to be more an artefact of sectioning, than a physiological result of dorsally synthesised cell wall hydrolases. The undisputed fact that during the later stages of malting, it is possible to wash out the dorsal area of the endosperm with warm water and vigourous shaking of the seeds, does not therefore allow conclusions to be made as to the physiological processes occurring in the early stages of germination. These processes must be studied by more direct techniques such as immunohistochemistry or specific histological techniques. 

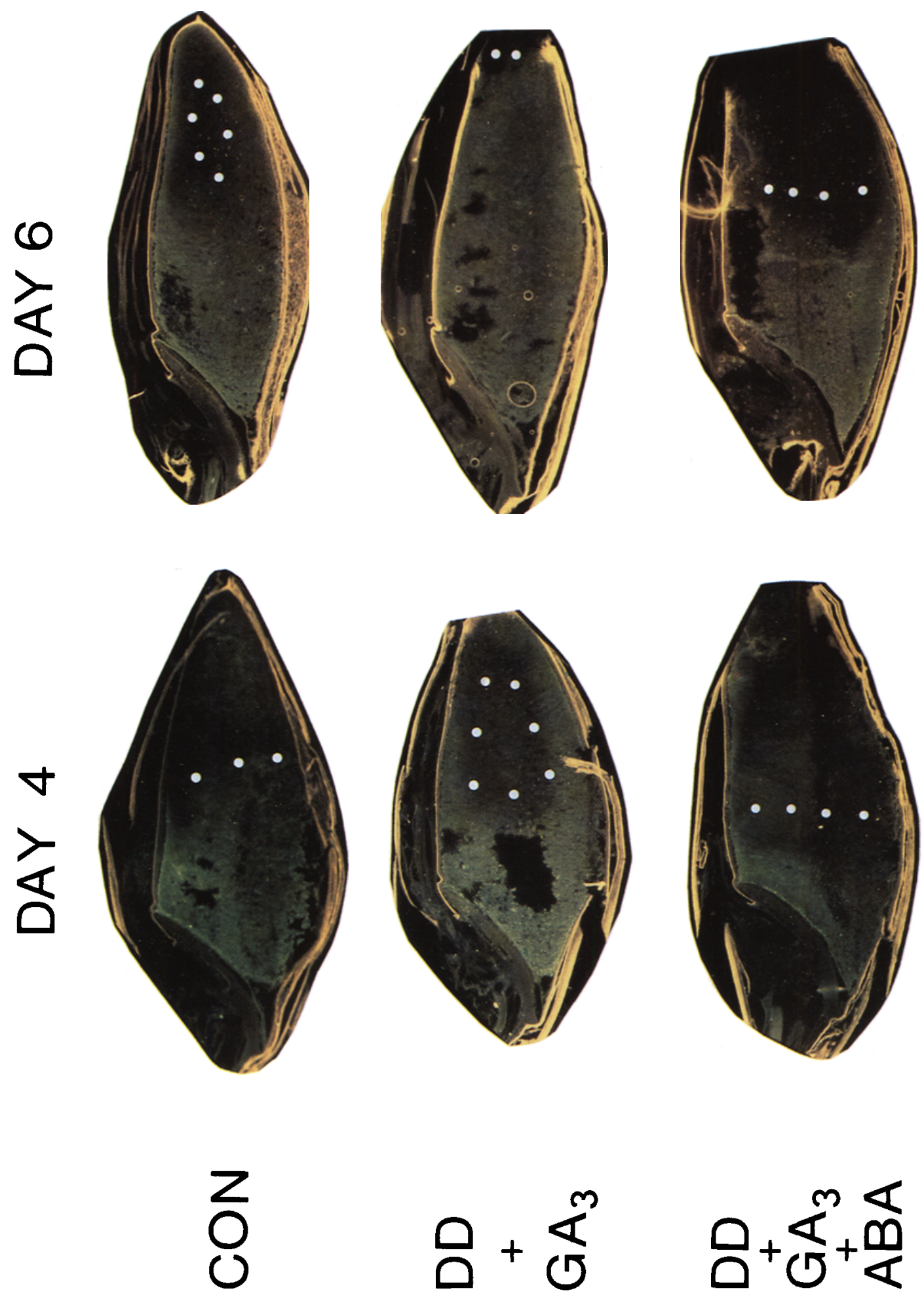

Figure 2. $\alpha-I I-\alpha$-amylase localisation in distally decapitated seeds.

The experiment was carried out as described in Figure 1. $\alpha$-II- $\alpha$-amylase was localized immunohistochemically as described in section 2.5. Con = whole seeds, distilled water; $D D+\mathrm{GA}_{3}=$ distally decapitated seeds, $10 \mu \mathrm{M}$ gibberellic acid: $\mathrm{DD}+\mathrm{GA}_{3}+\mathrm{ABA}=$ distally decapitated seeds, $10 \mu \mathrm{M}$ gibberellic acid and $50 \mu \mathrm{M}$ abscisic acid. The white dots on the photomicrographs indicate the limits of $\alpha$-II- $\alpha$-amylase transport. 
G. C. GibBons: Scutellum and aleurone during germination
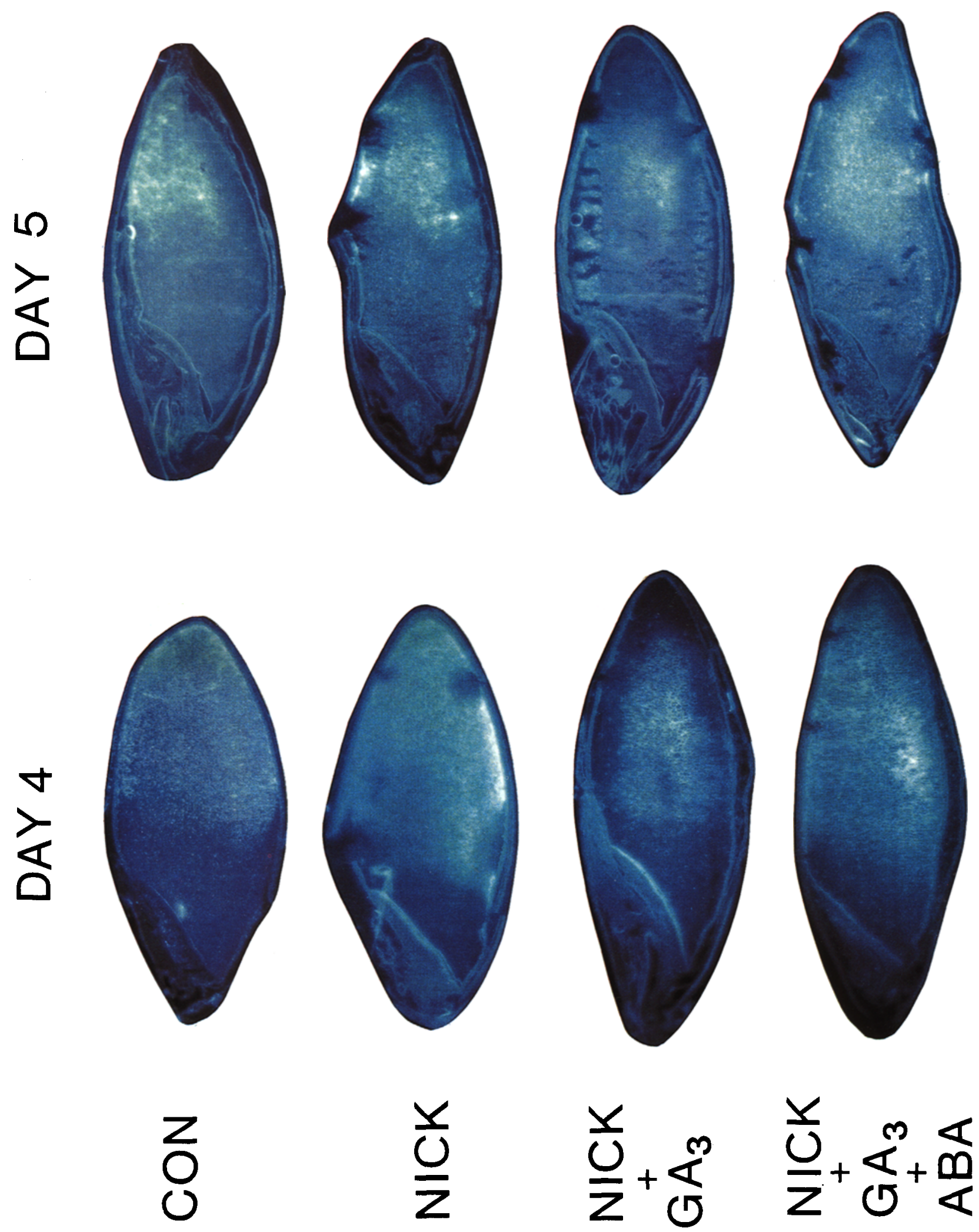
Figure 3. The effect of plant hormones on cell wall breakdown on the fourth and fifth day of germination in multiple incised (nicked) seeds.

Seeds were treated as described in section 3.2. and cell wall breakdown visualized as in section 2.6 . $\mathrm{Con}=$ whole seeds, distilled water; Nick $=$ nicked seeds, distilled water; Nick $+\mathrm{GA}_{3}=$ nicked seeds, $10 \mu \mathrm{M}$ gibberellic acid; Nick $+\mathrm{GA}_{3}+\mathrm{ABA}=$ nicked seeds, $10 \mu \mathrm{M}$ gibberellic acid and $50 \mu \mathrm{M}$ abscisic acid.

\subsection{Multiple incision experiment}

Although the distal decapitation experiment clearly showed that abscisic acid could negate the gibberellic acid induced production of hydrolases from the distal aleurone layer, there were some indications that abscisic acid was not reaching the median and proximal aleurone layer in an

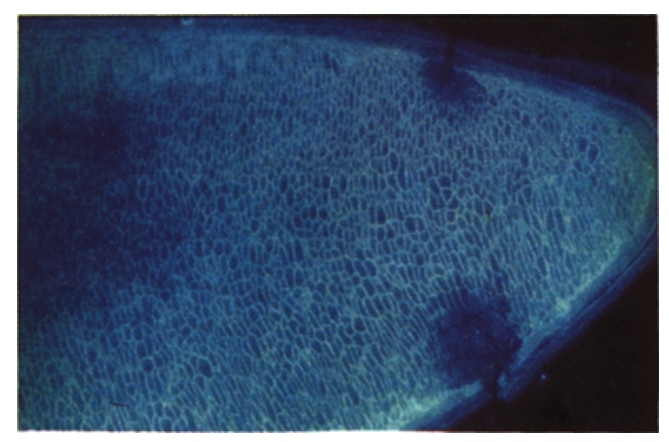

\section{A}
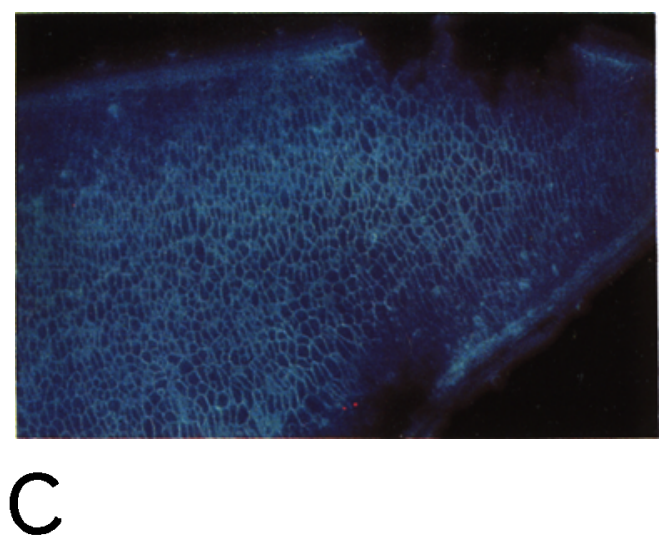

active inhibitory form. In order to assess the relative roles of the scutellum and aleurone layer during germination it was considered imperative that abscisic acid was given easy access to the aleurone layer close to the proximal and median areas of the seed as well as the scutellum. To achieve this aim, multiple incisions (nicks) were
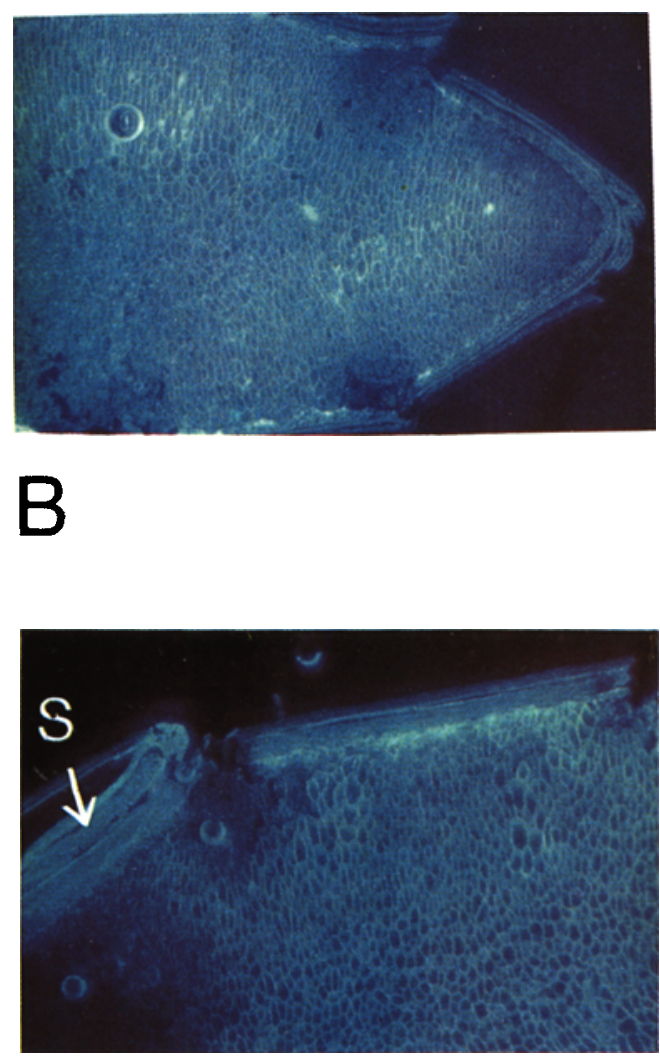

D

Figure 4. Detail of cell wall breakdown in nicked seeds.

The experimental conditions are described in section 3.2. A = distal end of nicked seed showing breakdown around incisions. $B=$ distal end of nicked seed germinating in the presence of $10 \mu \mathrm{M}$-gibberellic acid $+50 \mu \mathrm{M}$ abscisic acid. 3 days germination. $C=$ distal end of nicked seed germinating in $10 \mu \mathrm{m}$-gibberellic acid $+50 \mu \mathrm{M}$ abscisic acid. 5 days germination. $\mathrm{D}=$ detail of the area around a nick in the dorsal aleurone just above the scutellum (S) in a nicked seed germinated 3 days in the presence of $10 \mu \mathrm{M}$-gibberellic acid and $50 \mu \mathrm{M}$-abscisic acid. 
made in seeds prior to germination in such a way that the diffusion pathway for the added hormones was the shortest possible.

The pattern of cell wall breakdown observed in 4 day and 5 day germinated nicked seeds, treated with hormones, is shown in Figure 3. In some cases nicking resulted in a small amount of iocalised cell wail breakdown around the iesion. This is seen in the nicked 4 day and 5 day seeds germinated in the absence of hormones. The reason for this response is not fully understood, but may, as suggested by SMith and Briggs (24), be due to an enhancement of hydrolase production in the aleurone as a result of a higher availability of oxygen close to the lesion. This apparent increase in hydrolase synthesis around the nicks was limited, however, as seen in an enlargement of the distal part of another seed after 4 days of germination (Figure 4A) and may represent a direct wound response.

The addition of gibberellic acid to nicked grains stimulated synthesis and transport of cell wall breakdown hydrolases from the entire aleurone layer (Figure 3). This could be totally inhibited by concurrent addition of abscisic acid. Close examination around the lesions at 3 and 5 days of germination (Figures $4 B \& 4 C$ respectively) show the effectiveness of abscisic acid in inhibiting the effects of exogenous gibberellic acid on the distal aleurone. The absence of cell wall breakdown under the aleurone area proximal to the scutellum (Figure 4D) indicated that abscisic acid also effectively inhibited the effects of endogenous gibberellic acid on the aleurone mediated synthesis of cell wall breakdown hydrolases without affecting the scutellar mediated hydrolase synthesis and transport. The pattern of hydrolase transport in this treatment (nick + gibberellic acid + abscisic acid) approaches therefore the pattern of hydrolase transport resulting from the action of the scutellum alone.

\section{CONCLUSIONS}

The present experimental data indicate strongly that the barley scutellum is capable of synthesis and dissemination of cell wall breakdown enzymes and $\alpha$-II- $\alpha$-amylase, the major form of $\alpha$-amylase synthesised during germination. The scutellar production and transport of these hydrolases appear largely unaffected by external hormonal treatment of the germinating grain. The initial pattern and rate of endosperm transport of hydrolases is similar both in grains where the aleurone system is functional, and where the system has been inhibited. If it is assumed that the transport rate of the studied hydrolases is concentration dependent (ie. diffusion) then the scutellum appears to have the capacity to produce up to $50 \%$ of the total seed hydrolases ( $\alpha$-II- $\alpha$-amylase and cell wall breakdown enzymes) during the first 6 to 7 days of germination and seedling growth at $15^{\circ} \mathrm{C}$.

The barley cultivar used in the present experiments is one of the most common malting barley varieties in Denmark (Nordal). Although it has been suggested that the gibberellic acid response of the aleurone layer is essentially nonfunctional at $15^{\circ} \mathrm{C}(15,21)$, preliminary experiments with Nordal barley in this laboratory, indicate that $15^{\circ} \mathrm{C}$ should not be considered a sub-optimal temperature to measure gibberellic acid-induced production of hydrolases from the aleurone of Nordal barley. Therefore for this common malting barley the scutellum is initially the most important producer and disseminator of $\alpha$-II- $\alpha$-amylase and cell wall breakdown enzymes and is responsible for the production of up to one half of these enzymes during germination and early seedling growth. From the patterns of cell wall breakdown observed in a large number of European barley varieties, only a small number have been seen with a more effective aleurone hydrolase synthesis system. The physiological characteristics of those varieties are now under detailed study in this laboratory.

\section{ACKNOWLEDGEMENTS}

The author would like to thank Ms. LiSE Tang Petersen, Ms. Lisbeth Jensen, Ms. Maj Britt Nielsen, and Ms. Anette Hansen for excellent technical assistance. Thanks are also due to Dr. LaRs Munck for his help and encouragement during the course of work. Finally I wish to thank Ms. UlLA-KarIN GibBons for preparing the figures and Ms. Marianne Lumbye for typing the manuscript. 


\section{REFERENCES}

1. Aastrup S. \& K. ERdal: Quantitative determination of endosperm modification and its relationship to the content of $1,3: 1,4-\beta$-glucans during malting of barley. Carlsberg Res. Commun. 45 . 369-379 (1980)

2. Addicotr, F. T. \& J. L. Lyon: Physiology of abscisic acid and related substances. Ann. Rev. Plant Physiol. 20, 139-164 (1969)

3. BRIGGS, D. E.: a-amylase in germinating decorticated barley, II. Effects of physically damaging the grain. Phytochemistry 7, 531-538 (1968)

4. BRigGs, D. E.: Enzyme formation, cellular breakdown \& the distribution of gibberellins in the endosperm of barley. Planta 108, 351-358 (1972)

5. Brown, H. T. \& G. H. MORRIS: XXXResearches on the germination of some of the graminex. Part I. J. Chem. Soc. 57, 458-528 (1890)

6. Chrispeels, M. J. \& J. E. Varner: Inhibition of gibberellic acid induced formation of $\alpha$-amylase by abscisin II. Nature 212, 1066-1067 (1966)

7. Chrispeels, M. J. \& J. E. Varner: Hormonal control of enzyme synthesis: on the mode of action of gibberellic acid and abscisin in aleurone layers of barley. Plant Physiol. 42, 1008-1016 (1967)

8. Dashek W. V., B. N. Singh \& D. C. Walton: Metabolism and localization of abscisic acid in barley aleurone layers. Plant Physiol. 59(6) 76 (1977)

9. DURE, L. S.: Gross nutritional contribution of maize endosperm and scutellum to germination growth of maize axis. Plant Physiol. 35, $919-$ 925 (1960)

10. DuRE, L. S.: Site of origin and extent of activity of amylases in maize germination. Plant Physiol. $35,925-934$ (1960)

11. GibBons, G. C.: On the localisation and transport of $\alpha$-amylase during germination and early seedling growth of hordeum vulgare. Carlsberg Res. Commun. 44, 353-366 (1979)

12. Gibbons, G. C.: On the sequential determination of $\alpha$-amylase transport and cell wall breakdown in germinating seeds of hordeum vulgare. Carlsberg Res. Comm. 45, 177-184 (1980)

13. GibBons, G. C.: Rapid visualization of cell wall breakdown and alpha-amylase transport during malting of barley. European Brewery Convention, Monograph VI, 154-166 (1981)

14. Gillard. D. F. \& D. J. Walton: Abscisic acid metabolism by a cell-free preparation from echinocystis lobata liquid endosperm. Plant Physiol. 58, 790-795 (1976)

15. Goodwin, P. B. \& D. J. Carr: The induction of amylase synthesis in barley aleurone layers by gibberellic acid. I. Response to temperature. J. Exp. Botany 23, 1-7 (1972)

16. Haberlandt, G.: Die Kleberschicht des Grasendosperms als Diastase ausscheidendes Drüsengewebe. Ber. Deutch. Bot. Gesellsch. 8, 4048 (1980)

17. Ho, D. T.-H. \& J. E. VARNER: Response of barley aleurone layers to abscisic acid. Plant Physiol. 57. 175-178 (1976)

18. JACOBSEN, J. V.: Interactions between gibberellic acid, ethylene, and abscisic acid in control of amylase synthesis in barley aleurone layers. Plant Phsiol. 51, 198-202 (1973)

19. Mozer, T. J.: Control of protein synthesis in barley aleurone layers by the plant hormones gibberellic acid and abscisic acid. Cell 20.479485 (1980)

20. Окамото, K. \& T. Akazawa: Enzymic mechanisms of starch breakdown in germinating rice seeds. Plant Physiol. 63, 336-340 (1979)

21. Paleg, L. G.: Physiological effects of gibberellic acid. III. Observation on its mode of action on barley endosperm. Plant Physiol. 36, 829-837 (1961)

22. Palmer, G. H.: A method for direct assessment of malt modification. J. Inst. Brew. 81, 408-409 (1975)

23. Palmer, G. H. \& J. A. Taylor: Physiology of malting barley. Poster No. 54. 4th International Barley Genetics Symposium, Edinburgh (1981)

24. Smith, M. T. \& D. E. Briggs: The mechanisms by which tumbling and abrasion alter enzyme formation in malting grain. J. Inst. Brew. 85 . 160-167 (1979)

25. TANGL, E.: Studien über das Endosperm einiger Gramineen. Sitzber. der Wissensch. Akad. Wien 92, 72-109(1886)

26. Walton, D. C.: Biochemistry and physiology of abscisic acid. Ann. Rev. Plant. Physiol. 31, 453489 (1980) 